\title{
The Short- and Long-term Outcomes of Gastrectomy in Elderly Patients With Gastric Cancer
}

\author{
KEISUKE KOMORI ${ }^{1,2^{*}}$, KAZUKI KANO ${ }^{1,2^{*}}$, TORU AOYAMA ${ }^{1}$, ITARU HASHIMOTO ${ }^{1}$, \\ KENTARO HARA $^{1}$, MASAAKI MURAKAWA ${ }^{1}$, YOSUKE ATSUMI ${ }^{1}$, YUKIO MAEZAWA ${ }^{1}$, \\ KEISUKE KAZAMA ${ }^{1}$, MASAKATSU NUMATA ${ }^{1}$, HIROSHI TAMAGAWA ${ }^{1}$, \\ NORIO YUKAWA ${ }^{1}$, TAKASHI OSHIMA ${ }^{2}$, MUNETAKA MASUDA ${ }^{1}$ and YASUSHI RINO ${ }^{1}$ \\ ${ }^{1}$ Department of Surgery, Yokohama City University, Yokohama, Japan; \\ ${ }^{2}$ Department of Surgery, Kanagawa Cancer Center, Yokohama, Japan
}

\begin{abstract}
Background: The short- and long-term outcomes of gastrectomy in elderly patients with gastric cancer have not been fully evaluated. Patients and Methods: Patients who underwent gastrectomy were classified into two groups: Nonelderly patients $(<80$ years old) and elderly patients $(\geq 80$ years old). The surgical morbidity, overall and cancerspecific survival in the two groups were compared. Results: A total of 411 patients were evaluated. The rate of overall complication was $29.4 \%$ in the non-elderly and $32.4 \%$ in the elderly $(p=0.699)$. In the elderly, the overall and cancerspecific survival rates at 5 years after surgery were inferior to those of the younger group (59.8\% vs. 66.7\%, $p=0.103$ and $67.9 \%$ vs. $78.2 \%, p=0.028$, respectively). Conclusion: The short-term outcomes after gastrectomy were almost equal for the two groups in the present study. The prognosis was poor in elderly patients, especially those with advanced gastric cancer.
\end{abstract}

Gastric cancer is one of the main health problems (1). It is the fifth-most frequently diagnosed cancer and the third leading cause of cancer death worldwide. The 5-year survival rate ranges from $10.3 \%$ to $57.9 \%$ in all stages (1). Surgical resection is accepted as curative treatment for gastric cancer (2). However, complications after gastrectomy

This article is freely accessible online.

*These Authors contributed equally to this study.

Correspondence to: Toru Aoyama, Department of Surgery, Yokohama City University, 3-9 Fukuura, Kanazawa-ku, Yokohama 236-0004, Japan. Tel: +81 457872800, Fax: +81 457872931, e-mail: t-aoyama@lilac.plala.or.jp

Key Words: Gastric cancer, elderly patients, gastrectomy, short-term outcomes, long-term outcomes. remain a clinically relevant problem. Indeed, the morbidity and mortality after gastric resection have been reported in the range of $22.0-42.9 \%$ and $0 \%-0.8 \%$, respectively (3-6).

The number of elderly patients is increasing worldwide, with the proportion of elderly over 80 years old increasing at a rate of $4.0 \%$ annually (7). In elderly patients, conditions such as functional impairment and physiological problems are common, which can result in postoperative complications and poor survival (8-10). Surgical procedures, perioperative care, and surgical strategies should thus be carefully planned for elderly patients. However, there have been few previous studies reporting on the safety and feasibility of gastric cancer surgery for older patients. Furthermore, the long-term survival of elderly patients after gastric cancer surgery is largely still unknown.

It is therefore essential to clarify characteristics of elderly patients and assess the effect of age on their treatment outcomes. The present retrospective study compared the short- and long-term outcomes after gastric cancer surgery in elderly patients with those in non-elderly patients.

\section{Patients and Methods}

Patients. The study subjects were collected from among consecutive patients in the hospital registry indicated for gastric cancer surgery at the Yokohama City University Hospital between January 2000 and September 2012. Patients with the following were enrolled: Histologically proven gastric adenocarcinoma, no metachronous or concurrent malignancies, and gastrectomy for gastric cancer with curative D1+ or D2 dissection as a first-line treatment. The removed tumor specimens were examined histopathologically, and staging was performed based on tumor invasion and lymph node metastasis, in line with the criteria of the Third English Edition of the General Rules for Gastric Cancer, published by the Japanese Gastric Cancer Association (2).

Surgical procedure. All patients underwent total, distal, or proximal gastrectomy and lymphadenectomy for gastric cancer. As a general rule, D1+ dissection was performed for cT1N0 tumors, while D2 
Table I. A comparison of the baseline characteristics [n(\%)] for the whole cohort and according to age.

\begin{tabular}{|c|c|c|c|c|c|}
\hline Variables & & All patients $(n=411)$ & $<80$ years $(\mathrm{n}=377)$ & $\geq 80$ years $(\mathrm{n}=34)$ & $p$-Value \\
\hline Age, years & Median (range) & $69(29-89)$ & $68(29-79)$ & $82(80-89)$ & \multirow{3}{*}{0.296} \\
\hline \multirow[t]{2}{*}{ Gender, n (\%) } & Male & $311(75.6 \%)$ & $288(76.4 \%)$ & $23(67.6 \%)$ & \\
\hline & Female & $100(24.4 \%)$ & $89(23.6 \%)$ & $11(32.4 \%)$ & \\
\hline Body mass index, $\mathrm{kg} / \mathrm{m}$ & Median (range) & $22.6(13.8-35.5)$ & $22.4(18.7-35.5)$ & $23.0(13.8-31.0)$ & 0.873 \\
\hline \multirow{2}{*}{ ASA-PS, n (\%) } & 1,2 & $224(54.5 \%)$ & $212(56.2 \%)$ & $12(35.3 \%)$ & \multirow{2}{*}{0.030} \\
\hline & 3,4 & $187(45.5 \%)$ & $165(43.8 \%)$ & $22(64.7 \%)$ & \\
\hline \multirow[t]{3}{*}{ Co-morbidity, n (\%) } & Cardiovascular disease & $152(36.5 \%)$ & $132(35.0 \%)$ & $20(58.2 \%)$ & 0.009 \\
\hline & Respiratory disease & $27(6.6 \%)$ & $24(6.4 \%)$ & $3(8.8 \%)$ & 0.480 \\
\hline & Diabetes mellitus & $50(12.2 \%)$ & $44(11.7 \%)$ & $6(17.6 \%)$ & 0.281 \\
\hline \multirow[t]{3}{*}{ Site of tumor, n (\%) } & Upper & $109(26.5 \%)$ & $104(27.6 \%)$ & $5(14.7 \%)$ & \multirow{3}{*}{0.241} \\
\hline & Middle & $150(36.5 \%)$ & $138(36.6 \%)$ & $12(35.3 \%)$ & \\
\hline & Lower & $152(37.0 \%)$ & $135(35.8 \%)$ & $17(50.0 \%)$ & \\
\hline \multirow{2}{*}{ Histology, n (\%) } & Differentiated & $225(54.7 \%)$ & $201(53.3 \%)$ & $24(70.6 \%)$ & \multirow[t]{2}{*}{0.071} \\
\hline & Undifferentiated & $186(45.3 \%)$ & $176(46.7 \%)$ & $10(29.4 \%)$ & \\
\hline Tumor diameter, mm & Median (range) & $40(2-250)$ & $40(2-250)$ & $42(5-123)$ & 0.527 \\
\hline No. of harvested lymph nodes & Median (range) & $36(3-98)$ & $34(3-98)$ & $25(7-59)$ & 0.005 \\
\hline \multirow[t]{3}{*}{ Peritoneal lavage cytology, n (\%) } & Positive & $25(6.1 \%)$ & $23(6.1 \%)$ & $2(5.9 \%)$ & \multirow[t]{3}{*}{0.702} \\
\hline & Negative & $226(55.0 \%)$ & $205(54.4 \%)$ & $21(61.8 \%)$ & \\
\hline & Unknown & $160(38.9 \%)$ & $149(39.5 \%)$ & $11(32.3 \%)$ & \\
\hline \multirow{2}{*}{ Pathological T factor, n (\%) } & $\mathrm{T} 1$ & $213(51.8 \%)$ & $201(53.3 \%)$ & $12(35.3 \%)$ & \multirow{2}{*}{0.049} \\
\hline & $\mathrm{T} 2, \mathrm{~T} 3, \mathrm{~T} 4$ & $198(48.2 \%)$ & $176(46.7 \%)$ & $22(64.7 \%)$ & \\
\hline \multirow{2}{*}{ Pathological $\mathrm{N}$ factor, $\mathrm{n}(\%)$} & NO & $241(58.6 \%)$ & $226(59.9 \%)$ & $15(44.1 \%)$ & \multirow{2}{*}{0.101} \\
\hline & $\mathrm{N} 1, \mathrm{~N} 2, \mathrm{~N} 3$ & $170(41.4 \%)$ & $151(40.1 \%)$ & $19(55.9 \%)$ & \\
\hline \multirow[t]{2}{*}{ Pathological stage, n (\%) } & I & $233(56.7 \%)$ & $220(58.4 \%)$ & $13(38.2 \%)$ & \multirow[t]{2}{*}{0.072} \\
\hline & II, III, IV & $178(43.3 \%)$ & $157(41.6 \%)$ & $21(61.8 \%)$ & \\
\hline \multirow{2}{*}{ Lymphatic invasion, n (\%) } & Negative & $237(57.7 \%)$ & $223(59.2 \%)$ & $14(41.2 \%)$ & \multirow[t]{2}{*}{0.047} \\
\hline & Positive & $174(42.3 \%)$ & $154(40.8 \%)$ & $20(58.8 \%)$ & \\
\hline \multirow[t]{2}{*}{ Vascular invasion, $\mathrm{n}(\%)$} & Negative & $233(56.7 \%)$ & $220(58.4 \%)$ & $13(38.2 \%)$ & \multirow[t]{2}{*}{$\mathbf{0 . 0 3 0}$} \\
\hline & Positive & $178(43.3 \%)$ & $157(41.6 \%)$ & $21(61.8 \%)$ & \\
\hline
\end{tabular}

ASA-PS: American Society of Anesthesiologists Physical Status. Bold values indicate statistical significance.

was indicated for cN+ or cT2-T4 tumors, and the spleen was removed during total gastrectomy with lymphadenectomy.

Adjuvant treatment. Patients who were diagnosed with pStage II or III disease generally received adjuvant chemotherapy such as S-1, capecitabine plus oxaliplatin, and S-1 plus docetaxel based on clinical trials or common practice after July 2006. Within 6 weeks after surgery, the patients received 60,50 , or $40 \mathrm{mg}$ of S-1, depending on their body surface area, twice daily for 4 weeks followed by a 2 -week rest as a course (6-week schedule) or 2 weeks followed by a 1 -week rest as a course (3-week schedule) (11).

Follow-up. In principle, we followed-up patients at outpatient clinics. The blood test results, including tumor markers carcinoembryonic antigen (CEA) and carbohydrate antigen 19-9 (CA19-9), and clinical findings were evaluated at least once every 2 weeks in the S-1 treatment group. In the surgery-only group, patients visited the hospital for a re-examination at least once every 3 months for the first year after surgery. After the second year, all patients were followed-up in the same way. Recurrence was confirmed by imaging tests, such as computed tomography, ultrasonography, and endoscopy. Patients had at least one imaging examination every 6 months for the first 3 years after surgery and every year thereafter up to 5 years after surgery.

Definition of postoperative complications. Postoperative complications of grade 2-5 [in accordance with the Clavien-Dindo classification (12)] during the course of hospitalization or within 30 days after surgery were retrospectively determined from the patient's chart. We did not evaluate grade 1 complications in order to eliminate the chance of description bias from the patient's chart.

Evaluations and statistical analyses. The overall survival (OS) was defined as the time from surgery to death. The cancer-specific survival (CSS) was defined as the time from surgery to death from gastric cancer. The information on the patients who did not experience an event was collected on the last observation day. OS and CSS curves were calculated the using the Kaplan-Meier method and compared by log-rank test. Patients were divided into two groups: Non-elderly patients, $<80$ years old; and elderly patients, $\geq 80$ years old. Comparisons between the two groups were conducted using Student's $t$-test or the unpaired chi-squared method. A value of $p<0.05$ was considered statistically significant. The median with range, or frequency was used to describe the data. All data were analyzed using EZR (Jichi Medical University, Saitama, Japan) and R software (version 3.4.3) (13). The study was approved by the Institutional Review Board of Yokohama City University Hospital (B160707003).

\section{Results}

Patient characteristics. Four-hundred and eleven patients were included in this present study: 377 were non-elderly patients, while 34 were elderly. The demographic characteristics and clinicopathological findings of the 
Table II. A comparison of the surgical findings for the whole cohort and according to age.

\begin{tabular}{|c|c|c|c|c|c|}
\hline Variables & & All patients $(n=411)$ & $<80$ years $(n=377)$ & $\geq 80$ years $(n=34)$ & $p$-Value \\
\hline \multirow[t]{2}{*}{ Approach, n (\%) } & Open & $278(67.6 \%)$ & $250(66.3 \%)$ & $28(82.4 \%)$ & 0.058 \\
\hline & Laparoscopy & $133(32.4 \%)$ & $127(33.7 \%)$ & $6(17.6 \%)$ & \\
\hline \multirow[t]{4}{*}{ Type of surgery, n (\%) } & Distal gastrectomy & $225(54.8 \%)$ & $203(53.8 \%)$ & $22(64.7 \%)$ & 0.610 \\
\hline & Total gastrectomy & $158(38.4 \%)$ & $147(39.1 \%)$ & $11(32.3 \%)$ & \\
\hline & Proximal gastrectomy & $14(3.4 \%)$ & $13(3.4 \%)$ & $1(3.0 \%)$ & \\
\hline & Other & $14(3.4 \%)$ & $14(3.7 \%)$ & $0(0.0 \%)$ & \\
\hline \multirow[t]{2}{*}{ Lymph node dissection, $\mathrm{n}(\%)$} & D1+ & $209(50.9 \%)$ & $191(50.7 \%)$ & $18(52.9 \%)$ & 0.859 \\
\hline & D2 & $202(49.1 \%)$ & $186(49.3 \%)$ & $16(47.1 \%)$ & \\
\hline \multirow[t]{3}{*}{ Reconstruction, n (\%) } & Billroth-I & $189(46.0 \%)$ & $169(44.8 \%)$ & $20(58.8 \%)$ & 0.309 \\
\hline & Roux-Y & $205(49.9 \%)$ & $192(50.9 \%)$ & $13(38.2 \%)$ & \\
\hline & Other & $17(4.1 \%)$ & $16(4.3 \%)$ & $1(3.0 \%)$ & \\
\hline Operative time (min) & Median (range) & $317(107-800)$ & $320(107-800)$ & $248(112-502)$ & 0.004 \\
\hline Intraoperative blood loss (ml) & Median (range) & $350(0-4885)$ & $330(0-4000)$ & $356(35-4885)$ & 0.257 \\
\hline
\end{tabular}

Bold values indicate statistical significance.

Table III. Postoperative complications [n (\%)] for the whole cohort and according to age.

\begin{tabular}{|c|c|c|c|c|c|}
\hline Variables & & All patients $(n=411)$ & $<80$ years $(n=377)$ & $\geq 80$ years $(n=34)$ & $p$-Value \\
\hline \multirow[t]{13}{*}{ Surgical complication } & Overall & $122(29.7 \%)$ & $111(29.4 \%)$ & $11(32.4 \%)$ & 0.699 \\
\hline & Anastomotic leakage & $24(5.8 \%)$ & $18(4.8 \%)$ & $6(17.6 \%)$ & 0.009 \\
\hline & Pancreatic fistula & $19(4.6 \%)$ & $17(4.5 \%)$ & $2(5.9 \%)$ & 0.664 \\
\hline & Abdominal abscess & $14(3.4 \%)$ & $13(3.4 \%)$ & $1(2.9 \%)$ & 0.325 \\
\hline & Respiratory disease & $12(2.9 \%)$ & $12(3.1 \%)$ & $0(0.0 \%)$ & 0.610 \\
\hline & Anastomotic stenosis & $11(2.7 \%)$ & $11(2.9 \%)$ & $0(0.0 \%)$ & 0.611 \\
\hline & Ileus & $13(3.2 \%)$ & $10(2.7 \%)$ & $3(8.8 \%)$ & 0.261 \\
\hline & Surgical site infection & $7(1.7 \%)$ & $6(1.6 \%)$ & $1(2.9 \%)$ & 0.456 \\
\hline & Delirium & $6(1.5 \%)$ & $5(1.3 \%)$ & $1(2.9 \%)$ & 0.406 \\
\hline & Postoperative bleeding & $5(1.2 \%)$ & $5(1.3 \%)$ & $0(0.0 \%)$ & $>0.99$ \\
\hline & Chylous ascites & $5(1.2 \%)$ & $5(1.3 \%)$ & $0(0.0 \%)$ & $>0.99$ \\
\hline & Cardiovascular disease & $4(1.0 \%)$ & $4(1.1 \%)$ & $0(0.0 \%)$ & $>0.99$ \\
\hline & Other & $48(11.7 \%)$ & $46(12.2 \%)$ & $2(5.9 \%)$ & 0.404 \\
\hline \multirow[t]{2}{*}{ Mortality } & Yes & $2(0.5 \%)$ & $2(0.5 \%)$ & $0(0.0 \%)$ & $>0.99$ \\
\hline & No & $409(99.5 \%)$ & $375(99.5 \%)$ & $34(100.0 \%)$ & \\
\hline
\end{tabular}

Bold values indicate statistical significance.

patients are shown in Table I. The patients with an American Society of Anesthesiology (ASA) score $\geq 3$ were more frequent in the elderly group than in the non-elderly $(64.7 \%$ $v s .43 .8 \%$, respectively, $p=0.030$ ). The rate of cardiovascular disease was significantly higher in the elderly group than in the younger one $(35.0 \%$ vs. $58.2 \%, p=0.009)$.

Surgical and pathological findings. The intra-operative details are indicated in Table II. The median operative time was significantly longer in the elderly group (320 vs. $248 \mathrm{~min}$, respectively, $p=0.004)$. The proportion of patients with pathological stage I was higher in the non-elderly group than in the elderly one $(58.4 \% \mathrm{vs} .38 .2 \%, p=0.072)$. The median number of harvested lymph nodes was significantly fewer in the elderly group (25 vs. 34, $p=0.005)$. The proportions of patients with pathological T2 or more tumors and lymphatic and vascular invasion were significantly higher in the elderly group $(64.7 \%$ vs. $46.7 \%, p=0.049 ; 58.8 \%$ vs. $40.8 \%, p=0.047$; and $61.8 \%$ vs. $41.6 \%, p=0.030$, respectively).
Postoperative complications. The details of the postoperative complications are shown in Table III. The overall complication rate did not significantly differ $(p=0.699)$. Anastomotic leakage was the most frequently observed complication in both groups. There were significant differences between the groups in the anastomotic leakage rates, being lower in the non-elderly group (4.8\% vs. $17.6 \%, p=0.009)$. 30-Day mortality was confirmed in two patients because of respiratory disease and cardiovascular disease, respectively, in the non-elderly group $(0.5 \%)$ and was not observed at all in the elderly one.

Survival analyses. The median follow-up time was 50.2 months (range=0.3-122.0 months). The OS curves are shown in Figure 1. The OS curve for the elderly group was inferior to that of the younger one, although the OS rates at 5 years after surgery of $59.8 \%$ vs. $66.7 \%$ respectively, were not statistically significantly different $(p=0.103)$.

The CSS curves are shown in Figure 2. The CSS curve for the elderly group was inferior to that of the younger group; 


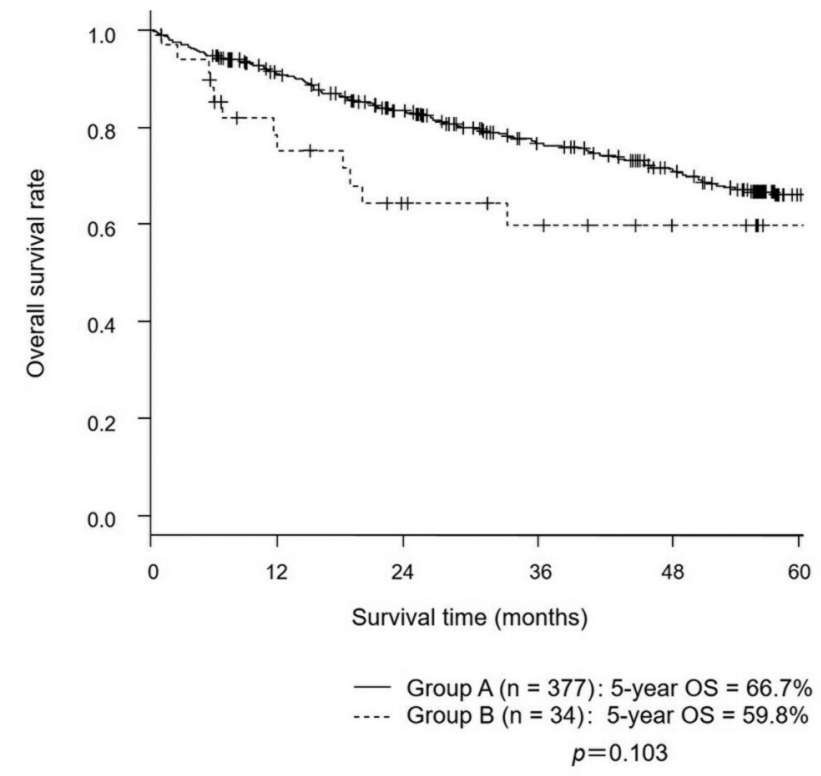

Figure 1. Overall survival of non-elderly (group A) and elderly (group $B)$ patients in the study groups.

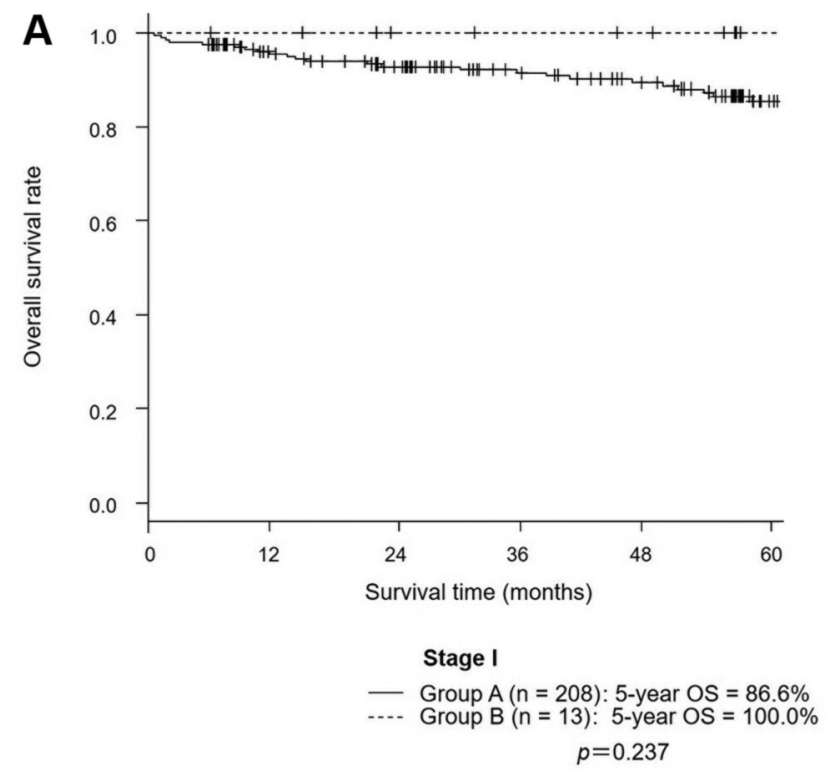

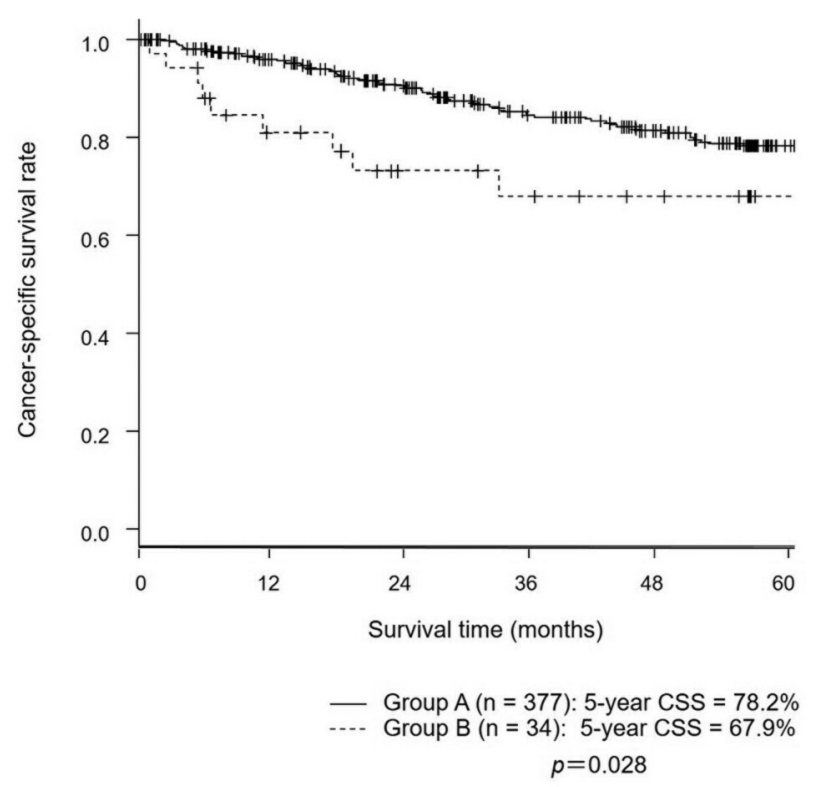

Figure 2. Cancer-specific survival in non-elderly (group A) and elderly (group B) patients in the study groups.

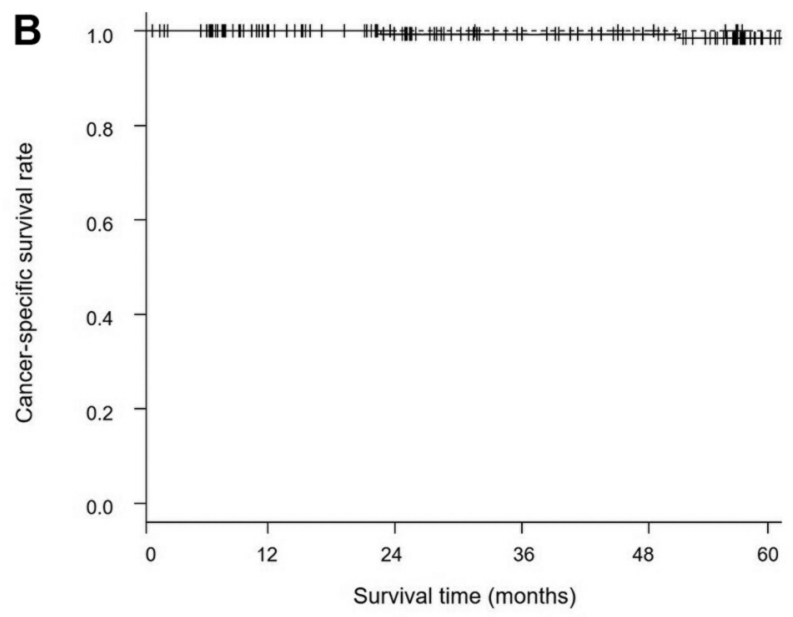

Stage I

- Group A $(n=208)$ : 5 -year CSS $=98.6 \%$ -..- Group B $(n=13)$ : 5-year CSS $=100.0 \%$ $p=0.752$

Figure 3. Overall (A) and cancer-specific (B) survival non-elderly (group A) and elderly (group B) patients with early gastric cancer.

this was reflected in the significantly lower CSS rate at 5 years after surgery $(67.9 \%$ vs. $78.2 \%$, respectively; $p=0.028)$.

Regarding early gastric cancer, the OS and CSS rates at 5 years after surgery for the elderly group were similar to those of the younger group ( $100.0 \%$ vs. $86.6 \%, p=0.237$; and $100.0 \%$ vs. $98.6 \%, p=0.752$; Figure 3 ). Regarding advanced gastric cancer, the OS and CSS rates at 5 years after surgery for the elderly group were inferior to those for the younger group ( $34.3 \%$ vs. $44.7 \%, p=0.045$; and $44.7 \%$ vs. $54.7 \%$, $p=0.050$, respectively; Figure 4).

Reasons for death and recurrence patterns. During the follow-up period, 82 patients $(20.0 \%)$ died of gastric cancer, and $50(12.2 \%)$ died of other causes (Table IV). The most 

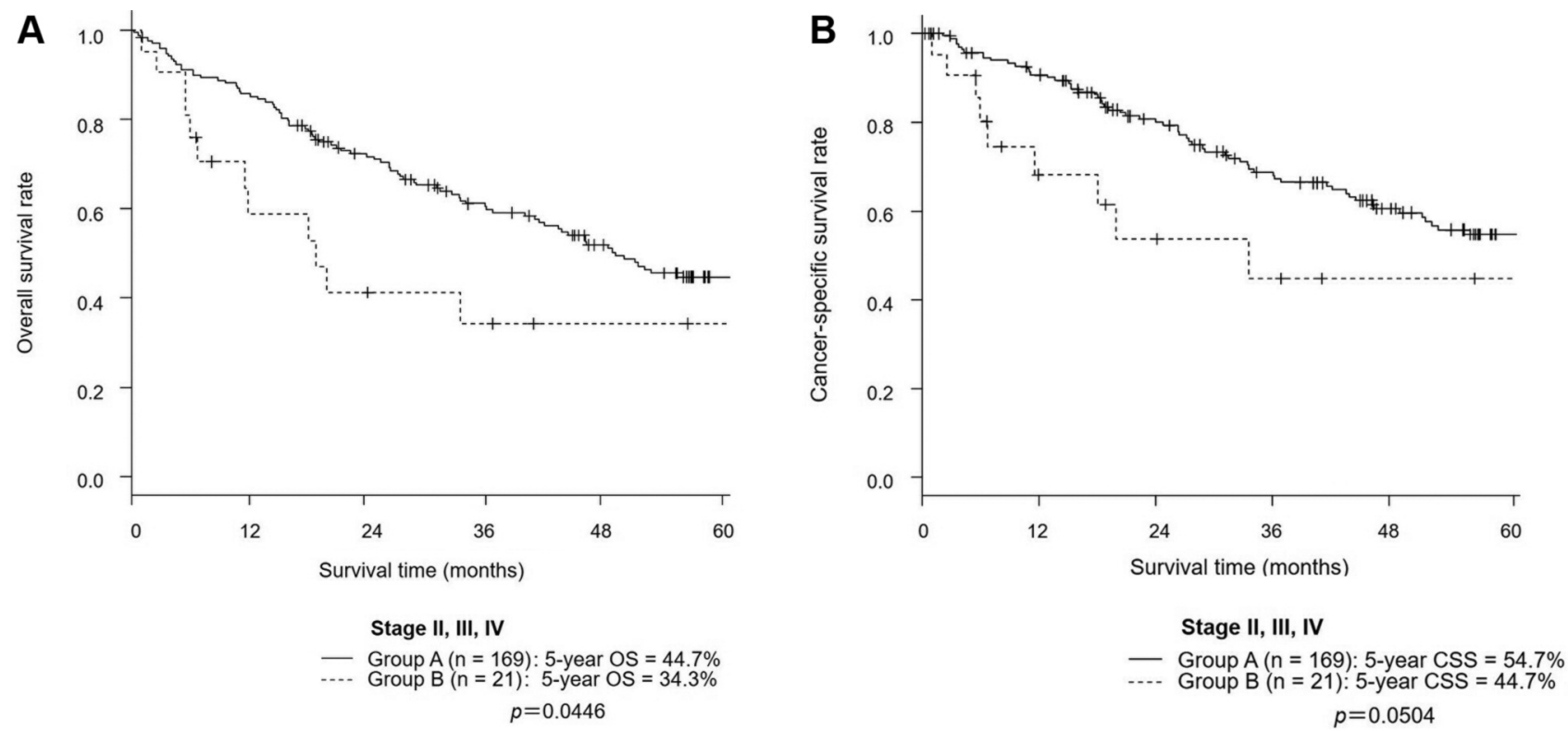

Figure 4. Overall (A) and cancer-specific (B) survival non-elderly (group A) and elderly (group B) patients with advanced gastric cancer.

Table IV. Postoperative outcomes [n (\%)] for the whole cohort and according to age.

\begin{tabular}{|c|c|c|c|c|c|}
\hline Variables & & All patients $(n=411)$ & $<80$ years $(\mathrm{n}=377)$ & $\geq 80$ years $(n=34)$ & $p$-Value \\
\hline \multirow[t]{3}{*}{ Cause of death } & Gastric cancer & $82(20.0 \%)$ & $73(19.4 \%)$ & $9(26.5 \%)$ & 0.369 \\
\hline & Other disease & $50(12.2 \%)$ & $47(12.5 \%)$ & $3(8.8 \%)$ & 0.784 \\
\hline & Unknown & $3(0.7 \%)$ & $3(0.8 \%)$ & $0(0.0 \%)$ & $>0.99$ \\
\hline \multirow[t]{5}{*}{ Recurrence site } & Peritoneal dissemination & $33(8.0 \%)$ & $30(8.0 \%)$ & $3(8.9 \%)$ & 0.746 \\
\hline & Hematogenous metastasis & $31(7.5 \%)$ & $30(8.0 \%)$ & $1(2.9 \%)$ & 0.497 \\
\hline & Lymph node & $10(2.5 \%)$ & $8(2.1 \%)$ & $2(5.9 \%)$ & 0.197 \\
\hline & Locoregional & $1(0.2 \%)$ & $0(0.0 \%)$ & $1(2.9 \%)$ & 0.083 \\
\hline & Unknown & $3(0.7 \%)$ & $2(0.5 \%)$ & $1(2.9 \%)$ & 0.229 \\
\hline
\end{tabular}

common sites of recurrence were the peritoneum $(19.0 \%)$, hematogenous sites $(8.0 \%)$, lymph nodes $(7.5 \%)$, and local recurrences $(2.5 \%)$, in order of frequency. There were no significant differences between two groups in the reasons for recurrence or death patterns.

\section{Discussion}

In the present study, we retrospectively investigated whether or not gastrectomy for patients $\geq 80$ years old with gastric cancer was safe and feasible compared with non-elderly patients. Although our study showed similar findings for elderly and non-elderly patients in the short-term outcomes of gastrectomy, the long-term survival was worse in elderly patients, especially for those with advanced gastric cancer, than in non-elderly patients. Our results therefore suggest that gastrectomy for gastric cancer is a safe option with similar benefits in the short term, regardless of the age of the patient, but surgical indications for elderly patients with advanced gastric cancer should be carefully considered.

In the present study, the short-term results were not significantly different between elderly and non-elderly patients. Some authors reported similar results. For example, Nakanoko et al. (14) evaluated 41 patients $\geq 80$ years old and 430 patients $<80$ years old who underwent gastrectomy for gastric cancer and found no significant difference in the incidence of postoperative complications (12.8\% vs. 9.8\%). Similarly, Kim et al. (15) analyzed 31 elderly patients and 404 younger patients and reported that postoperative complications at rates of $16.1 \%$ and $11.9 \%$, respectively $(p=0.565)$.

In contrast, the rate of anastomotic leakage was higher in the elderly patients than in the non-elderly ones in the present study (17.6\% vs. $4.8 \%, p=0.009)$. Cardiovascular disease and high ASA scores were previously reported as risk 
factors for anastomotic leakage. Kim et al. (16) reported that preoperative cardiovascular disease was an independent risk factor for anastomotic leakage (odds ratio=1.826, 95\% interval confidence $=1.088-3.067 ; p<0.001)$. In addition, Vural et al. (17) reported that a high ASA score ( $\geq 3$ ) was significantly associated with an increased rate of postoperative complications compared with a low ASA score $(\leq 2)$ (odds ratio=2.285, $p=0.033$ ). In our study, the ratio of preoperative cardiovascular disease to a high ASA score was significantly higher in the older patients than in the younger ones ( $p=0.009$ and $p=0.006$, respectively), which may have resulted in the occurrence of anastomotic leakage.

In the present study, the 5-year OS and CSS rates were worse in the elderly patients, especially those with advanced gastric cancer, than in the non-elderly patients. However, some authors have reported different results. Isobe et al. reported that the OS and CSS rates in the most elderly ( $\geq 85$ years old, $n=56)$ and elderly (80-84 years old, $n=161)$ patients at 3 years after gastrectomy for gastric cancer were not significantly different $(70.1 \%$ vs. $68.5 \%, p=0.885$; and $73.8 \%$ vs. $72.6 \%, p=0.984$, respectively) (18). Mengardo et al. also reported that elderly patients ( $\geq 80$ years old, $n=75$ ) who underwent gastrectomy for gastric cancer had similar 5year OS and CSS rates to younger patients [70-79 years $(\mathrm{n}=166), p=0.107$; and $\leq 69$ years $(\mathrm{n}=226), p=0.319$ ] (19).

However, other authors have reported that a worse ASA score, an advanced pathological stage, and infectious complications are associated with worse long-term outcomes in elderly patients with gastric cancer than those in nonelderly patients (19-21). Mengardo et al. found that the 5year OS rate was significantly lower in elderly patients $(>80$ years: $16 \%)$ than in non-elderly patients $[(\leq 69$ years: $38 \%)$ and 70-79 years: $48 \% ; p=0.024)$ when analyzing only patients who underwent gastrectomy for gastric cancer with an ASA score of 3-4 (19). Tokunaga et al. reported that patients with postoperative intraperitoneal complications (pancreas-related complications, anastomotic leakage, and intra-abdominal abscess) had a worse 5-year OS rate than those without such complications (66.4\% vs. $86.8 \%$, $p<0.001)$ (21). In the present study, the ASA score and pathological stage were worse in elderly patients than in younger ones ( $p=0.006$ and 0.072 , respectively), and the rate of intra-abdominal complications (anastomotic leakage, abdominal abscess, and pancreatic fistula) was higher in elderly patients than non-elderly patients (20.6\% vs. $9.8 \%$, $p=0.075$ ), which may have resulted in worse OS and CSS rates in elderly patients than in younger ones.

Several limitations associated with the present study warrant mention. Therefore, special care must be taken when interpreting our findings. Initially, a relatively small sample of elderly patients $(n=34)$ was enrolled in this study. In addition, the indication of surgery was determined by the operator's preference. This study may therefore have selection bias. For example, advanced gastric cancer was more frequently observed in the elderly patients than in the non-elderly patients. Minimally invasive treatment, such as endoscopic treatment, was likely prioritized over surgical resection for early gastric cancer in elderly patients. Furthermore, surgery was often indicated for advanced cancer with life-threatening symptoms, such as anemia and stenosis, even when considering the risks of surgery. Secondly, the period of this study was relatively long (about 12 years). Steady improvement of operative devices and regimens for chemotherapy during this period may have affected the result. Thirdly, this study may have had selection bias because no standard treatment, such as adjuvant chemotherapy or chemotherapy, has been established for cases of relapse in elderly patients, and the indication of chemotherapy was determined by the physician's preference. This may therefore have affected the results. Given these limitations, the current results need to be tested in other cohort series.

In summary, gastrectomy for gastric cancer is a safe option with similar benefits in the short term regardless of a patient's age; however, surgical indications for elderly patients with advanced gastric cancer should be carefully considered.

\section{Conflicts of Interest}

The Authors have no conflicts of interest to declare regarding this study.

\section{Authors' Contributions}

$\mathrm{KK}, \mathrm{KK}$ and TA contributed to the conception and design of the study. KK, KK, TA, IH, KH, MM, YA, YM, KK, MN, MM and YR contributed to the data collection and assembly. All of the Authors contributed to the data acquisition and interpretation of the analyzed data. KK and KK wrote the article. All of the Authors contributed to the critical revision of the article. All of the Authors read and approved the final article.

\section{References}

1 Bray F, Ferlay J, Soerjomataram I, Siegel RL, Torre LA and Jemal A: Global cancer statistics 2018: GLOBOCAN estimates of incidence and mortality worldwide for 36 cancers in 185 countries. CA Cancer J Clin 68(6): 394, 2018. PMID: 30207593. DOI: $10.3322 /$ caac. 21492

2 Japanese Gastric Cancer Association: Japanese Classification of Gastric Carcinoma: Third English Edition. Gastric Cancer 14: 101-112, 2011. PMID: 21573743. DOI: 10.1007/s10120-0110041-5

3 Tsuburaya A, Mizusawa J, Tanaka Y, Fukushima N, Nashimoto A and Sasako M: Neoadjuvant chemotherapy with S-1 and cisplatin followed by D2 gastrectomy with para-aortic lymph node dissection for gastric cancer with extensive lymph node metastasis. Br J Surg 101(6): 653-660, 2014. PMID: 24668391. DOI: $10.1002 /$ bjs. 9484 
4 Nashimoto A, Nakajima T, Furukawa H, Kitamura M, Kinoshita T, Yamamura Y, Sasako M, Kunii Y, Motohashi H and Yamamoto S: Randomized trial of adjuvant chemotherapy with mitomycin, fluorouracil, and cytosine arabinoside followed by oral fluorouracil in serosa-negative gastric cancer: Japan Clinical Oncology Group 9206-1. J Clin Oncol 21(12): 2282-2287, 2003. PMID: 12805327 . DOI: 10.1200/JCO.2003.06.103

5 Sano T, Sasako M, Yamamoto S, Nashimoto A, Kurita A, Hiratsuka M, Tsujinaka T, Kinoshita T, Arai K, Yamamura Y and Okajima K: Gastric cancer surgery: Morbidity and mortality results from a prospective randomized controlled trial comparing D2 and extended para-aortic lymphadenectomy-Japan Clinical Oncology Group study 9501. J Clin Oncol 22(14): 2767-2773, 2004. PMID: 15199090 . DOI: 10.1200/JCO.2004.10.184

6 Sasako M, Sano T, Yamamoto S, Sairenji M, Arai K, Kinoshita T, Nashimoto A and Hiratsuka M: Left thoracoabdominal approach versus abdominal-transhiatal approach for gastric cancer of the cardia or subcardia: A randomised controlled trial. Lancet Oncol 7(8): 644-651, 2006. PMID: 16887481. DOI: 10.1016/S1470-2045(06)70766-5

7 DESA's Population Division: The World Population Prospects: 2015 Revision 2015. https://www.un.org/en/development/desa/ publications/world-population-prospects-2015-revision.html [Last accessed on 29th April 2020]

8 Hamel MB, Henderson WG, Khuri SF and Daley J: Surgical: outcomes for patients aged 80 and older: morbidity and mortality from major noncardiac surgery. J Am Geriatr Soc 53(3): 424, 2005. PMID: 15743284. DOI: 10.1111/j.1532-5415.2005. 53159.x

9 Fleisher LA, Fleischmann KE, Auerbach AD, Barnason SA, Beckman JA, Bozkurt B, Davila-Roman VG, Gerhard-Herman MD, Holly TA, Kane GC, Marine JE, Nelson MT, Spencer CC, Thompson A, Ting HH, Uretsky BF and Wijeysundera DN: 2014 ACC/AHA guideline on perioperative cardiovascular evaluation and management of patients undergoing noncardiac surgery: Executive summary: A report of the American College of Cardiology/American Heart Association Task Force on Practice Guidelines. Circulation 130(24): 2215, 2014. PMID: 25085962. DOI: $10.1161 /$ CIR.0000000000000105

10 Smetana GW, Lawrence VA, Cornell JE and American College of Physicians: Preoperative pulmonary risk stratification for noncardiothoracic surgery: systematic review for the American College of Physicians. Ann Intern Med 144(8): 581, 2006. PMID: 16618956. DOI: 10.7326/0003-4819-144-8-20060418000009

11 Sakuramoto S, Sasako M, Yamaguchi T, Kinoshita T, Fujii M, Nashimoto A, Furukawa H, Nakajima T, Ohashi Y, Imamura H, Higashino M, Yamamura Y, Kurita A, Arai K and ACTS-GC Group: Adjuvant chemotherapy for gastric cancer with S-1, an oral fluoropyrimidine. N Engl J Med 357(18): 1810-1820, 2007. PMID: 17978289. DOI: 10.1056/NEJMoa072252

12 Dindo D, Demartines N and Clavien PA: Classification of surgical complications: A new proposal with evaluation in a cohort of 6336 patients and results of a survey. Ann Surg 240(2): 205-213, 2004. PMID: 15273542. DOI: 10.1097/01.sla. 0000133083.54934.ae
13 Kanda Y: Investigation of the freely available easy-to-use software 'EZR' for medical statistics. Bone Marrow Transplant 48: 452-458, 2013. PMID: 23208313. DOI: 10.1038/bmt. 2012.244

14 Nakanoko T, Kakeji Y, Ando K, Nakashima Y, Ohgaki K, Kimura Y, Saeki H, Oki E, Morita M and Maehara Y: Assessment of surgical treatment and postoperative nutrition in gastric cancer patients older than 80 years. Anticancer Res 35(1): 511-515, 2015. PMID: 25550596.

$15 \mathrm{Kim}$ MS and Kim S: Outcome of gastric cancer surgery in elderly patients. J Gastric Cancer 16(4): 254-259, 2016. PMID: 28053812. DOI: 10.5230/jgc.2016.16.4.254

16 Kim SH, Son SY, Park YS, Ahn SH, Park DJ and Kim HH: Risk factors for anastomotic leakage: A retrospective cohort study in a single gastric surgical unit. J Gastric Cancer 15(3): 167-175, 2015. PMID: 26468414. DOI: 10.5230/jgc.2015.15.3.167

17 Vural S, Civil O, Kement M, Altuntas YE, Okkabaz N, Gezen C, Haksal M, Gundogan E and Oncel M: Risk factors for early postoperative morbidity and mortality in patients underwent radical surgery for gastric carcinoma: A single-center experience. Int J Surg 11(10): 1103-1109, 2013. PMID: 24075931. DOI: 10.1016/j.ijsu.2013.09.008

18 Isobe T, Hashimoto K, Kizaki J, Miyagi M, Aoyagi K, Koufuji $\mathrm{K}$ and Shirouzu K: Surgical procedures, complications, and prognosis for gastric cancer in the very elderly $(>85)$ : A retrospective study. Kurume Med J 59(3-4): 61-70, 2012. PMID: 23823016. DOI: $10.2739 /$ kurumemedj.59.61

19 Mengardo V, Cormack OM, Weindelmayer J, Chaudry A, Bencivenga M, Giacopuzzi S, Allum WH and de Manzoni G: Multicenter study of presentation, management, and postoperative and long-term outcomes of septegenerians and octogenerians undergoing gastrectomy for gastric cancer. Ann Surg Oncol 25(8): 2374-2382, 2018. PMID: 29868974. DOI: 10.1245/s10434-018-6543-1

20 Seo HS, Jung YJ, Kim JH, Park CH and Lee HH: Necessity of D2 lymph node dissection in older patients $\geq 80$ years with gastric cancer. J Geriatr Oncol 9(2): 115-119, 2018. PMID: 28988631. DOI: 10.1016/j.jgo.2017.09.006

21 Tokunaga M, Tanizawa Y, Bando E, Kawamura T and Terashima M: Poor survival rate in patients with postoperative intraabdominal infectious complications following curative gastrectomy for gastric cancer. Ann Surg Oncol 20(5): 1575-1583, 2013. PMID: 23076557. DOI: 10.1245/s10434-012-2720-9
Received April 9, 2020

Revised April 26, 2020 Accepted April 29, 2020 